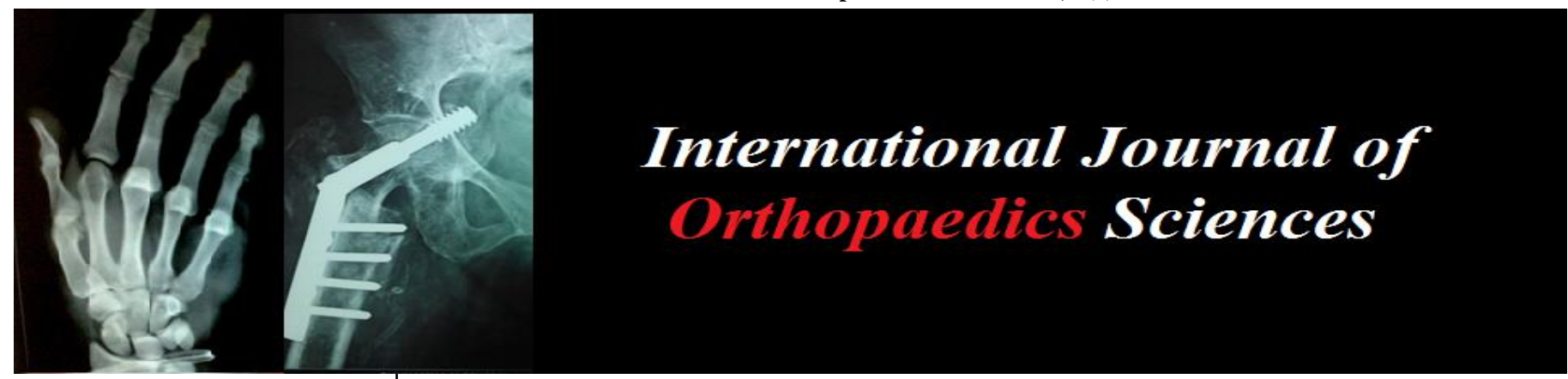

E-ISSN: 2395-1958

P-ISSN: 2706-6630

IJOS 2021; 7(3): 809-812

(C) 2021 IJOS

www.orthopaper.com

Received: 15-05-2021

Accepted: 18-06-2021

Dr. B Sachidanand Rai

Professor, Department of

Orthopedics, Srinivas Institute

of Medical Sciences, Mangalore,

Karnataka, India
Corresponding Author: Dr. B Sachidanand Rai Professor, Department of Orthopedics, Srinivas Institute of Medical Sciences, Mangalore, Karnataka, India

\section{Functional outcome of lumbar spine disorders treated with laminectomy}

\section{Dr. B Sachidanand Rai}

DOI: https://doi.org/10.22271/ortho.2021.v7.i31.2840

\section{Abstract}

Patients with multiple levels of stenosis had somewhat less severe pain at baseline on the SF-36 bodily pain scale compared to one and two levels. Patients with single level stenosis were less likely to present with neurogenic claudication $(\mathrm{p}<0.001)$ and more likely to report dermatomal pain radiation. Other baseline symptoms were similar across groups. When comparing surgical to conservative treatments for one, two and three level isolated stenosis, there was a significant surgical treatment effect in most outcomes measures within each subgroup at each time point. The only significant difference in treatment effects between subgroups was at two years for patient satisfaction with symptoms.

Keywords: Functional outcome, lumbar spine, laminectomy

\section{Introduction}

Laminectomy is the procedure of choice especially in the elderly. The central spinal stenosis denotes the involvement of the area between the facet joints, which includes dura and its contents. the reasons for the stenosis here are protruding disc, bulging annulus, osteophyte formation or thickened ligamentum flavum central canal stenosis clinically presents as claudication and the lateral canal stenosis presents as radiculopathy the lateral recess also referred as lee's entrance zone, begins from lateral border of dura and extends to medial border of pedicle. This is where the nerve root exits. Zones of lateral canal is divided into entrance zone, mid zone and the exit zone the reason for stenosis here are lateral disc herniation, thickened ligamentum flavum extending into the foramen, facet arthritis or Spondylolisthesis ${ }^{[1-10]}$. Weinstein JN, et al. ${ }^{[11]}$. Combined the randomized and observational cohorts of patients with spinal stenosis $(\mathrm{SpS})$, those treated surgically showed significantly greater improvement in pain, function, satisfaction, and self-rated progress over four years compared to patients treated non-operatively. Results in both groups were stable between two and four years. Park et al. ${ }^{[12]}$ did retrospective comparative study looking at the SPORT study results to determine the effect of multilevel stenosis on surgical and conservative treatment outcomes. Amundsen et al. ${ }^{[13]}$ dis a case control, comparative study of 100 patients with symptomatic spinal stenosis Atlas SJ et al. ${ }^{[14]}$ did a study on long term outcome of surgical and non-surgical management of lumbar canal stenosis 8 to 10 years of follow-up. The present study is done to find out the functional outcome of lumbar spine disorders treated with laminectomy.

\section{Aims and objectives}

To study of functional outcome of lumbar spine disorders treated with laminectomy.

Materials and methods

This study was done in Department of Orthopedics, Srinivasan Institute of Medical Sciences, Mangalore. Thirty people who were treated with laminectomy procedures were selected randomly and the functional scores were studied.

\section{Inclusion criteria}

1. Degenerative Lumbar spine stenosis 


\section{Exclusion criteria}

1. Old fracture spine

This is a description study and the functional outcome of the study is described in this study.

\section{Results}

Table 1: Mean age of the population

Mean age $\quad$ STD Deviation 48.83 years

\begin{tabular}{|c|c|}
\hline Mean age & STD Deviation \\
\hline 48.83 years & \pm 3.76 years \\
\hline
\end{tabular}

Table 2: Sex ratio

\begin{tabular}{|c|c|}
\hline Male & Female \\
\hline 23 & 07 \\
\hline
\end{tabular}

Table 3: Spine Flexion

\begin{tabular}{|c|c|}
\hline Restricted & $\mathbf{2 5}$ \\
\hline Not restricted & 05 \\
\hline
\end{tabular}

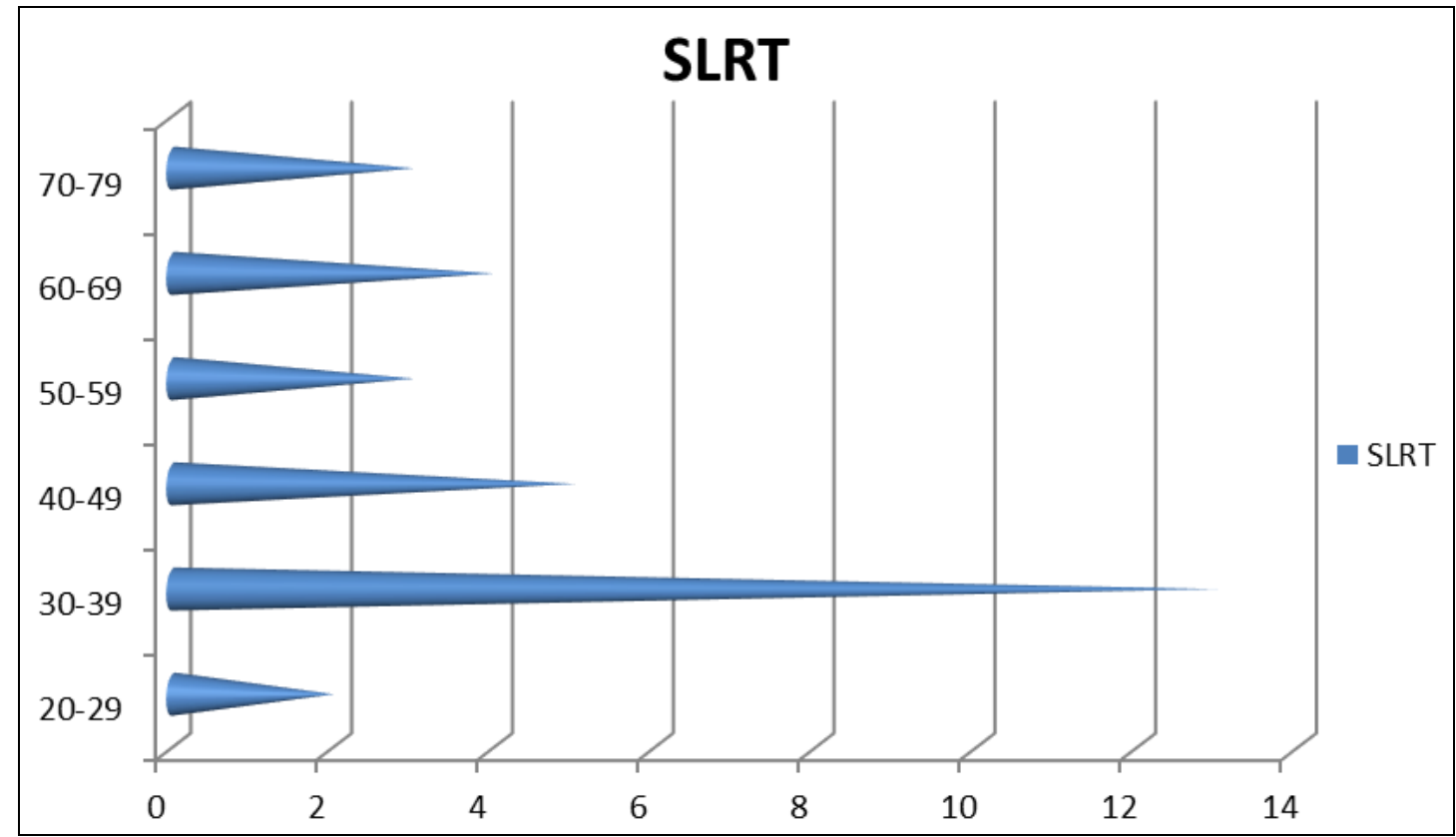

Graph 1: SLRT

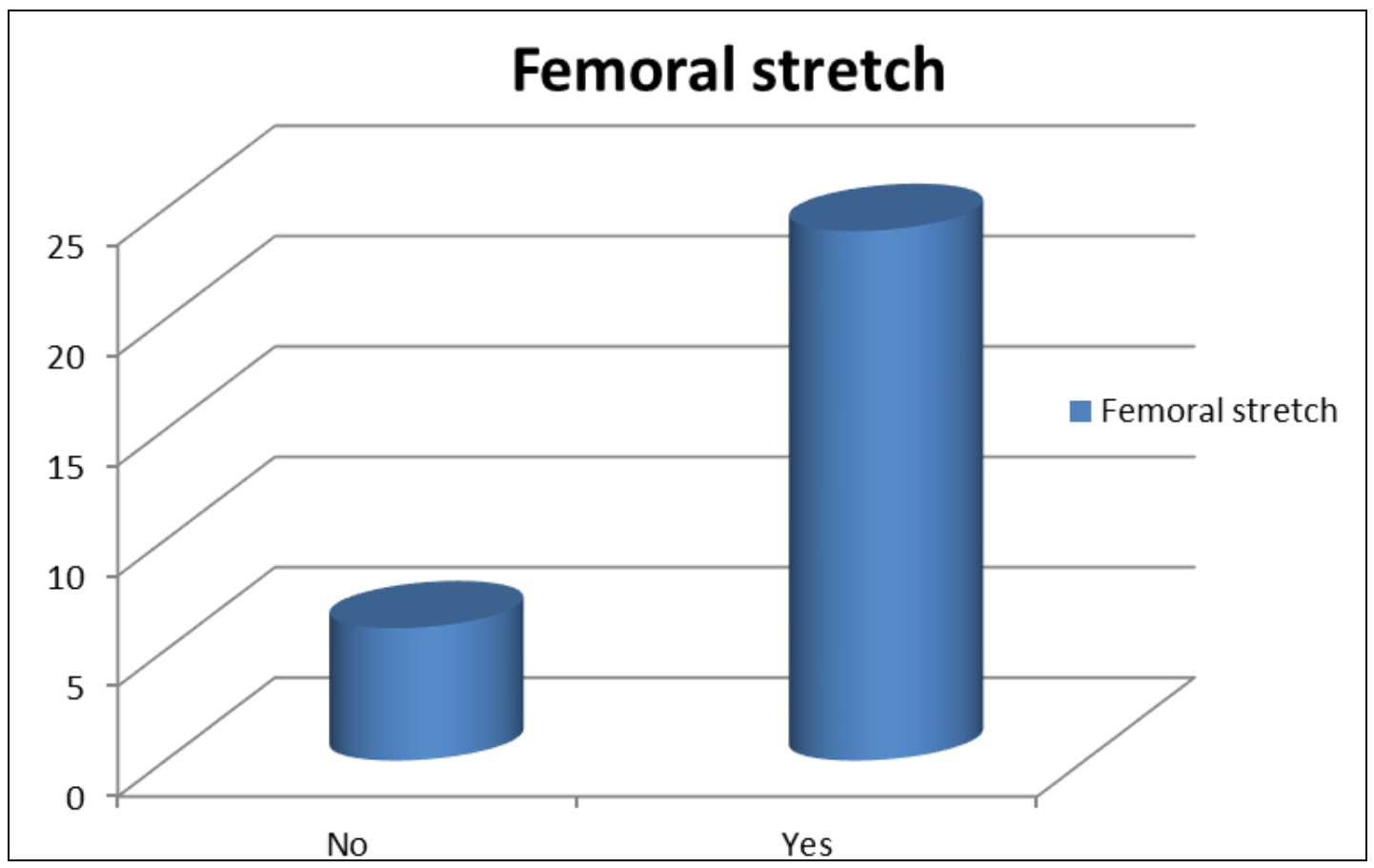

Graph 2: Femoral Stretch test 


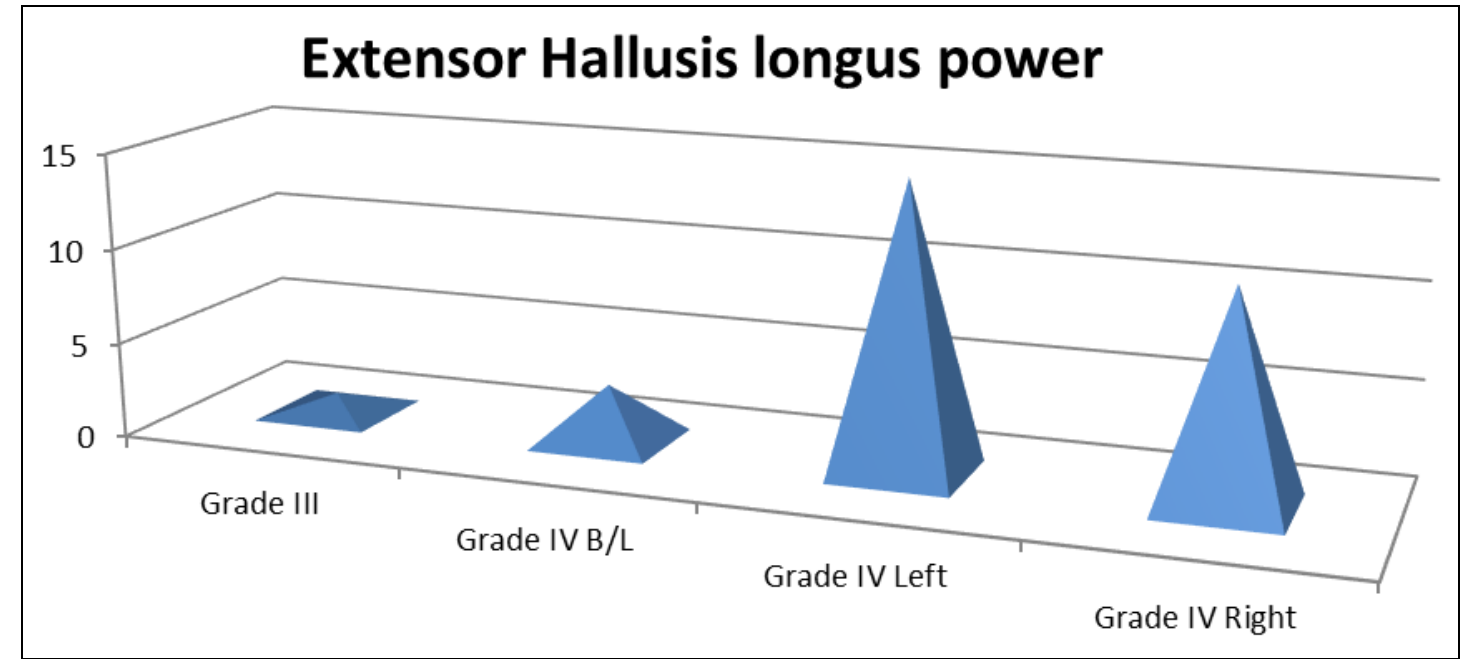

Graph 3: Extensor Hallusis Longus Power

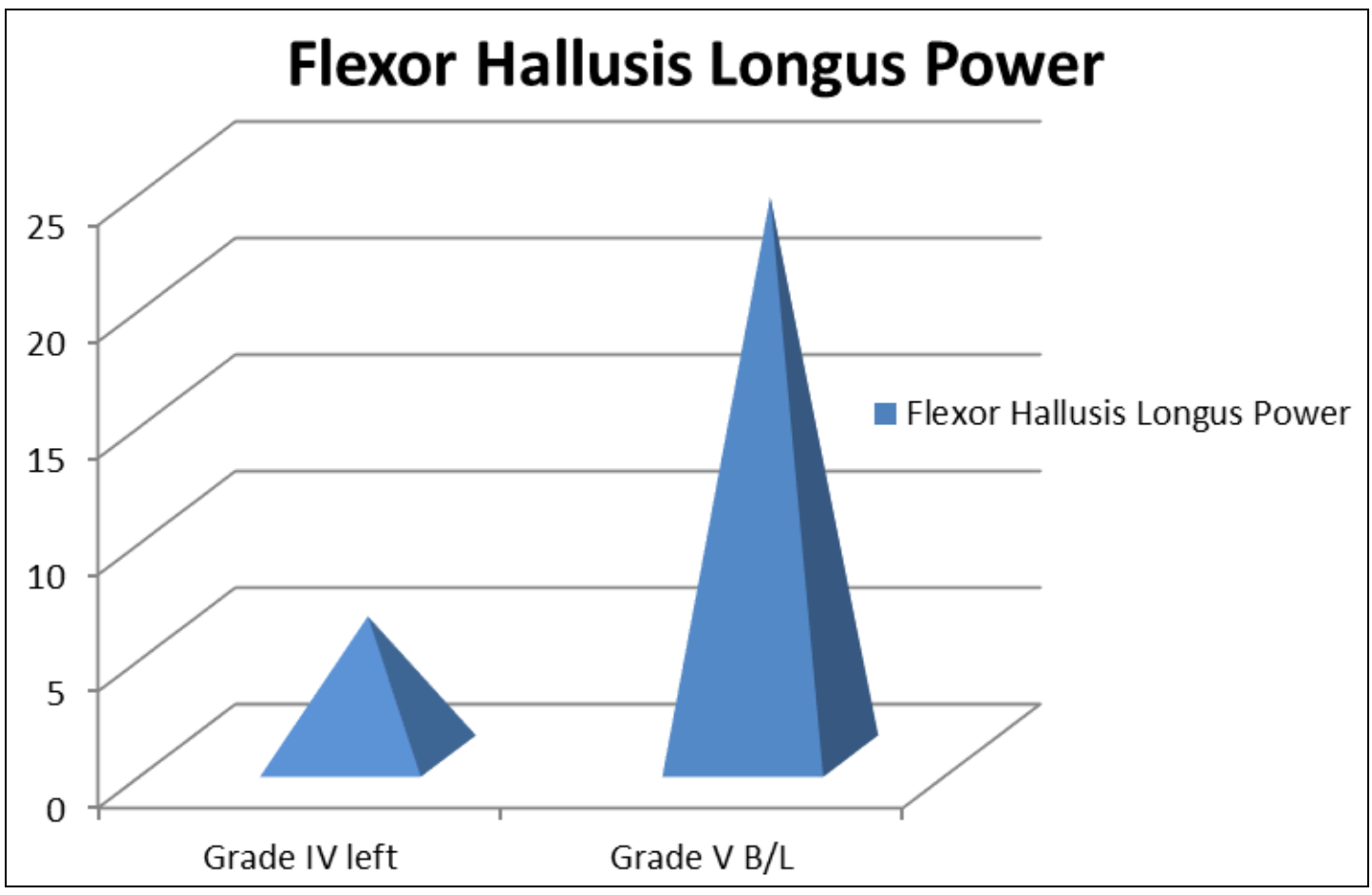

Graph 4: Flexor Hallusis Longus Power

\section{Discussion}

According a retrospective, prognostic study of the effects of age on decompressive surgery for lumbar spinal stenosis. 283 patients were grouped according to age. One group was aged 65-74 years old and the second group was > 75-years-old. Follow-up was up to 42 months with a minimum of nine months. Within both treatment groups there was a significant $(p<0.0001)$ subjective improvement in low back and radicular pain as well as the ability to perform daily activities. When compared to preoperative levels, the oral scores for pain while performing daily activities were significantly improved $(p<0.0001)$ in both treatment groups. The authors concluded that the overall postoperative complication rate was similar between the groups and that age is not a contraindication for surgical decompression of lumbar spinal stenosis. Both groups are equally likely to suffer minor perioperative complications.

\section{Conclusion}

In this study the functional outcome was better.

\section{References}

1. Svensson HO, Andersson GB. Low-back pain in 40- to 47-year-old men: work history and work environment factors Spine. 1983;8(3):272-6.

2. Svensson HO, Andersson GB. The relationship of lowback pain, work history, work environment, and stress, A retrospective cross-sectional study of 38- to 64yearold women Spine. 1989;14(5):517-22.

3. PFU Jr MD. Orthopedic Surgeon. Lumbar Spinal Stenosis: A Definitive Guide [Internet] Spine-health, [Cited 2016 Nov 25]. Available from: http://www.spinehealth.com/conditions/spinalstenosis/lumbarspinalstenosis-a-definitive-guide

4. Medtronic. Lumbar Spinal Stenosis Treatment \& Symptoms | Back.com [Internet], [Cited 2016 Nov 25]. Available from:

http://www.back.com/backpain/conditions/lumbarspinalstenosis/index.htm

5. Ise $\mathrm{S}$, Abe K, Orita S, Ishikawa T, Inage K, Yamauchi K et al. Surgical treatment for far-out syndrome associated with abnormal fusion of the L5 vertebral corpus and L4 
hemivertebra: a case report, BMC Res Notes [Internet] 2016, 9. [Cited 2016 Nov 26], Available from: http://www.ncbi.nlm.nih.gov/pmc/articles/PMC492430 8/

6. Atlas SJ, Keller RB, Wu YA, Deyo RA, Singer DE. Long-term outcomes of surgical and nonsurgical management of lumbar spinal stenosis: 8 to 10 year results from the Maine lumbar spine study Spine. 2005;30(8):936-43.

7. Caputy AJ, Luessenhop AJ. Long-term evaluation of decompressive surgery for degenerative lumbar stenosis, J Neurosurg. 1992;77(5):669-76.

8. The Natural Course of Lumbar Spinal Stenosis: Clinical Orthopaedics and Related Research [Internet] LWW, [Cited 2016 Dec 1], Available from: http://journals.lww.com/corr/Fulltext/1992/06000/The_N atural_Course_of_Lumbar_Spinal_Stenosis_.10.aspx

9. Yuan PS, Booth RE, Albert TJ. Nonsurgical and surgical management of lumbar spinal stenosis Instar Course Lect. 2005;54:303-12.

10. Roland Morris Disability Questionnaire [Internet]. [cited 2016 Dec 1], Available from: http://www.rmdq.org/

11. Weinstein JN, Lurie JD, Tosteson TD, Skinner JS, Hanscom B, Tosteson ANA et al. Surgical vs nonoperative treatment for lumbar disk herniation: the Spine Patient Outcomes Research Trial (SPORT) observational cohort JAMA. 2006;296(20):2451-9.

12. Park DK, An HS, Lurie JD, Zhao W, Tosteson A, Tosteson TD et al. Does multilevel lumbar stenosis lead to poorer outcomes: A sub analysis of the Spine Patient Outcomes Research Trial (SPORT) lumbar stenosis study Spine. 2010;35(4):439-46.

13. Amundsen $\mathrm{T}$, Weber $\mathrm{H}$, Nordal HJ, Magnaes $\mathrm{B}$, Abdelnoor M, Lilleâs F. Lumbar spinal stenosis: conservative or surgical management?: A prospective 10year study Spine. 2000;25(11):1424-1435-1436.

14. Epstein NE. Spine surgery in geriatric patients: Sometimes unnecessary, too much, or too little Surg Neurol Int [Internet] 2011, 2, [Cited 2016 Nov 29]. 